\title{
Adsorption of Methylene Blue by Imperata Cylindrica: Reaction Optimization by Response Surface Methodology (RSM)
}

\author{
N. F. M. Salleh ${ }^{1,}$, F. F. Asmori2, N. M. Shukri' , S. F. M. Hanafiah ${ }^{1}$ \\ ${ }^{1}$ School of Health Sciences, Universiti Sains Malaysia, Health Campus, 16150 Kubang Kerian, Kelantan, Malaysia. \\ ${ }^{2}$ Faculty of Chemical and Natural Resources Engineering, Universiti Malaysia Pahang, 26300 Gambang, Pahang, Malaysia.
}

\begin{abstract}
Imperata Cylindrica (IC) is a solid waste that is readily available throughout the year known as one of the most important weed in the world and frequently causes major disposal issues. As a result, using $\mathrm{IC}$ as a low-cost adsorbent is beneficial from both, economic and environmental standpoint to remove colors from wastewater of textile industry. This work studies the reaction optimization of methylene blue (MB) removal using IC by response surface methodology (RSM). The RSM experiments were designed with 4 independent variables (initial adsorbent dosage, initial $\mathrm{pH}$, initial dye concentration, and initial temperature) and 1 response variable (percent removal of $\mathrm{MB}$ ). According to the pareto figure, the initial $\mathrm{pH}$ demonstrated the greatest impact on the percent removal of $\mathrm{MB}$. The RSM data predicted the optimum condition of MB removal up to $86.61 \%$ using $\mathrm{IC}$, by utilizing adsorbent dosage of $1.458 \mathrm{~g} / \mathrm{L}$, at $42{ }^{\circ} \mathrm{C}$, initial $\mathrm{pH}$ of 6.8 and $\mathrm{MB}$ concentration of $235 \mathrm{ppm}$. The chacterization analysis revealed the physicochemical properties of IC in the adsoprtion process.
\end{abstract}

ARTICLE HISTORY

Received: 10 Oct. 2021

Revised: 27 Oct. 2021

Accepted: 1 Nov. 2021

\section{KEYWORDS}

Imperata Cylindrica

Methylene Blue

Optimization

Response Surface

Methodology

\section{INTRODUCTION}

The textile dyeing process is the most unfriendly industrial process for the environment, and it is one of the factors that contributes to the water pollution. This procedure entails the creation of coloured wastewater, which contains a large number of high-concentration, complex components, and unmanageable organic compounds, and it is critical to remove dyes as soon as possible [1].Various conventional techniques are available for color removals from coloured wastewater, such as adsorption, ion exchange, cougulation, and membrane technology [2-4]. Among others, adsorption has emerged as one of the most useful and comparably low-cost method for the decolorization of coloured wastewater. Adsorption of aqueous effluents by activated carbon is a popular treatment technology that has been utilised for a number of separation and purification procedures in industrial operations. On the other hand, activated carbon is a costly material and its regeneration for reuse adds to the price [5].

In recent years, a variety of agricultural products and by-products have been studied to eliminate dye, including rubberleaf powder, spent grain, residual biogas slurry, and rice husk owing to the advatages of small initial costs and investments [6-9]. Imperata Cylindrica (IC), cogongrass as perennial grasses is an agricultural waste which is abundantly available throughout the year [10]. Therefore, finding applications for this waste would be beneficial from both an environmental and economic standpoint.

The ability of the IC as the low-cost adsorbent was studied for the removal of oil, heavy metals, and methylene blue [11-13]. However, several details of the adsorption process cannot be observed due to the limitation of the classical method. Therefore, this study aims to examine the optimum conditions of the removal of MB from aqueous solution by IC using RSM. In addition, using RSM, the effects of variables, the relationship between variables and response, and the optimum conditions of variables wereexamined from a small number of experiments. Interestingly, this is the first study conducted using FCCD, whereas previous researchers only focused on the factorial design of RSM [14].

\section{Chemicals}

Methylene blue (MB, $\mathrm{C}_{16} \mathrm{H}_{18} \mathrm{~N}_{3} \mathrm{SCl}, 319.86 \mathrm{~g} / \mathrm{mol}, 668 \mathrm{~nm}$ ), sodium hydroxide $(\mathrm{NaOH})$, and hydrochloric acid ( $\mathrm{HCl}$ ) were purchased from Merck (M) Sdn. Bhd. Malaysia. All chemicals used in this work were spectroscopic grade with ultra-high purify (99.9\%).

\section{Adsorbent (Imperata Cylindrica) Preparation}

The IC was collected around Kg. Kayu Besar, Kota Bharu, Kelantan. It was chopped into 1-2 cm long pieces, soaked in water overnight to eliminate any contaminants adhering to the surface, and then oven-dried for 24 hours at $80{ }^{\circ} \mathrm{C}$. The particles were crushed and sieved until they were uniformly 355-600 $\mathrm{m}$ in size. Finally, the powder was stored in a bottle as an adsorbent. 


\section{Characterization of Imperata Cylindrica}

The functional groups in the IC powder were identified using Fourier Transform Infrared (FTIR) analysis in the 4000$400 \mathrm{~cm}^{-1}$ range. The morphological feature of the samples were identified using scanning electron microscopy (SEM) with a $15 \mathrm{kV}$ accelerating voltage.

\section{Adsorption Experiment}

Adsorption experiment was conducted according to the operating parameters designed by RSM, as listed in Table 2 . In brief, specific amount of IC powder was added in a $250 \mathrm{~mL}$ conical flask containing $200 \mathrm{~mL}$ of MB solution with specific concentration. The $\mathrm{pH}$ of $\mathrm{MB}$ solution was adjusted using $\mathrm{HCl}$ and $\mathrm{NaOH}$. The adsorption process was conducted under constant stirring at a rate of $300 \mathrm{rpm}$ at specific temperature until it reached equilibrium. The sample was then taken at the proper time and centrifuged for 15 minutes at $3500 \mathrm{rpm}$. A UV-vis spectrophotometer was used to quantify the residual MB concentration. All of the experiments were carried out in triplicates. The MB removal percentages were calculated using Equation (1).

$$
\text { Percentage removal }(\%)=\frac{C_{o}-C_{t}}{C_{t}} \times 100
$$

Where $\mathrm{C}_{\mathrm{o}}(\mathrm{mg} / \mathrm{L})$ and $\mathrm{C}_{\mathrm{t}}(\mathrm{mg} / \mathrm{L})$ are the initial concentration and concentration at any time, respectively.

\section{Experimental Design and Optimization}

RSM analysis using a face-centered central composite design (FCCD) was conducted using design expert software. The ranges and coded levels of the variables are listed in Table 1 . The total number of tests undertaken was 26 , with 24 factorial points, 8 axial points, and 2 replicates at the centre points.

Table 1. Coded levels for independent variables.

\begin{tabular}{lllll}
\hline & Symbol & \multicolumn{3}{c}{ Coded levels } \\
\cline { 3 - 5 } Independent variables & & -1 & 0 & 1 \\
\hline Absorbent dosage $(\mathrm{g} / \mathrm{L})$ & $X_{1}$ & 0.3 & 1.125 & 2 \\
Initial pH & $X_{2}$ & 2 & 5 & 8 \\
Initial concentration $(\mathrm{ppm})$ & $X_{3}$ & 50 & 225 & 400 \\
Temperature $\left({ }^{\circ} \mathrm{C}\right)$ & $X_{4}$ & 30 & 40 & 50 \\
\hline
\end{tabular}

\section{EXPERIMENTAL DESIGN AND OPTIMIZATION}

\section{RSM analysis}

Table 2 displays the experimental design and outcomes of the MB removal experiment using IC as low-cost adsorbent. The quadratic model for the percent removal of MB is described in Equation (2), which is based on the RSM analysis:

$$
\begin{aligned}
\mathrm{Y}= & 80.96+5.04 X_{1}+18.63 X_{2}-2.89 X_{3}-0.04 X_{4}-6.97 X_{1} X_{2}+5.57 X_{1} X_{3}+1.47 X_{1} X_{4} \\
& +4.37 X_{2} X_{3}+0.63 X_{2} X_{4}-2.27 X_{3} X_{4}-9.60 X_{1}^{2}-15.48 X_{2}^{2}+1.99 X_{3}^{2}-1.02 X_{4}^{2}
\end{aligned}
$$

where $Y$ is a predicted percent removal of MB.

The percent removal of MB as seen in Figure 1 was compared to the projected values attained from Equation (2). The coefficient of determination $\left(R^{2}\right)$ value for percent removal of MB is 0.9419 , suggesting that the model accounts for $94.19 \%$ of the variability in the data. The empirical model is sufficient to elucidate the majority of the variability in essay reading, which should be at least 0.75 or more. Table 3 reveals that the F-value for percent removal of $M B\left(F_{0.05}=2.74\right)$ is greater than the tabulated F-value $\left(\mathrm{F}_{0.05}=2.74\right)$. The model derived by Equation (2) can be concluded to give good predictions at a $5 \%$ level of significance. 
Table 2. Experimental design and result of the response surface design.

\begin{tabular}{|c|c|c|c|c|c|c|c|c|c|}
\hline & \multicolumn{8}{|c|}{ Manipulated variables } & \multirow{2}{*}{$\begin{array}{c}\text { Response } \\
\text { Percentage } \\
\text { removal of MB } \\
(\%)\end{array}$} \\
\hline No & $X_{1}(\mathrm{~g})$ & Level & $X_{2}(\mathrm{pH})$ & Level & $X_{3}(\mathrm{ppm})$ & Level & $X_{4}\left({ }^{\circ} \mathrm{C}\right)$ & Level & \\
\hline 1 & 0.25 & -1 & 2 & -1 & 50 & -1 & 30 & -1 & 44.915 \\
\hline 2 & 0.25 & -1 & 2 & -1 & 50 & -1 & 50 & 1 & 43.615 \\
\hline 3 & 0.25 & -1 & 2 & -1 & 400 & 1 & 30 & -1 & 10.06 \\
\hline 4 & 0.25 & -1 & 2 & -1 & 400 & 1 & 50 & 1 & 8.464 \\
\hline 5 & 0.25 & -1 & 8 & 1 & 50 & -1 & 30 & -1 & 79.412 \\
\hline 6 & 0.25 & -1 & 8 & 1 & 50 & -1 & 50 & 1 & 74.576 \\
\hline 7 & 0.25 & -1 & 8 & 1 & 400 & 1 & 30 & -1 & 82.335 \\
\hline 8 & 0.25 & -1 & 8 & 1 & 400 & 1 & 50 & 1 & 77.992 \\
\hline 9 & 2 & 1 & 2 & -1 & 50 & -1 & 30 & -1 & 41.667 \\
\hline 10 & 2 & 1 & 2 & -1 & 50 & -1 & 50 & 1 & 48.837 \\
\hline 11 & 2 & 1 & 2 & -1 & 400 & 1 & 30 & -1 & 58.046 \\
\hline 12 & 2 & 1 & 2 & -1 & 500 & 1 & 50 & 1 & 48.407 \\
\hline 13 & 2 & 1 & 8 & 1 & 50 & -1 & 30 & -1 & 62.406 \\
\hline 14 & 2 & 1 & 8 & 1 & 50 & -1 & 50 & 1 & 79.152 \\
\hline 15 & 2 & 1 & 8 & 1 & 400 & 1 & 30 & -1 & 76.987 \\
\hline 16 & 2 & 1 & 8 & 1 & 400 & 1 & 50 & 1 & 74.096 \\
\hline 17 & 0.25 & -1 & 5 & 0 & 225 & 0 & 40 & 0 & 59.388 \\
\hline 18 & 2 & 1 & 5 & 0 & 225 & 0 & 40 & 0 & 81.823 \\
\hline 19 & 1.125 & 0 & 2 & -1 & 225 & 0 & 40 & 0 & 48.568 \\
\hline 20 & 1.125 & 0 & 8 & 1 & 225 & 0 & 40 & 0 & 80.884 \\
\hline 21 & 1.125 & 0 & 5 & 0 & 50 & -1 & 40 & 0 & 89.086 \\
\hline 22 & 1.125 & 0 & 5 & 0 & 400 & 1 & 40 & 0 & 75.303 \\
\hline 23 & 1.125 & 0 & 5 & 0 & 225 & 0 & 30 & -1 & 79.223 \\
\hline 24 & 1.125 & 0 & 5 & 0 & 225 & 0 & 50 & 1 & 79.142 \\
\hline 25 & 1.125 & 0 & 5 & 0 & 225 & 0 & 40 & 0 & 83.216 \\
\hline 26 & 1.125 & 0 & 5 & 0 & 225 & 0 & 40 & 0 & 83.216 \\
\hline
\end{tabular}

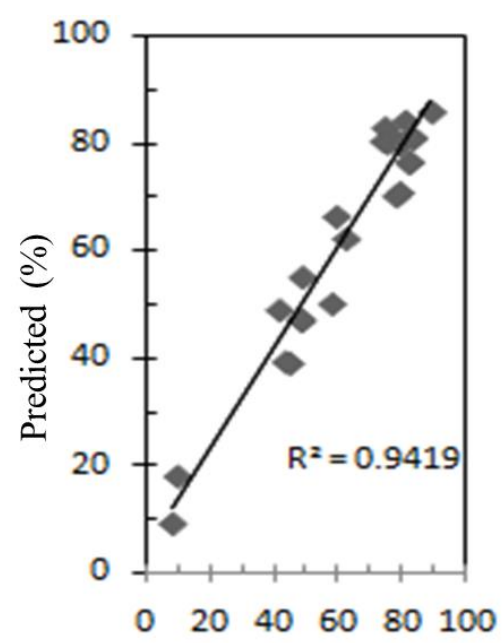

Observed (\%)

Figure 1. Parity plot for the observed and predicted values for reduction of MB 
The analysis of variance (ANOVA) is shown in Table 3. The F-value for percent removal of MB is higher than the calculated $\mathrm{F}$-value $\left(\mathrm{F}_{0.05}=2.74\right)$. The big value of $\mathrm{F}$ suggests that the regression equation can explain the majority of the variation in the response. At a $5 \%$ level of significance, the model generated from Equation (4) can be concluded to give good predictions.

Table 3. ANOVA for percentage removal of MB model.

\begin{tabular}{|c|c|c|c|c|c|}
\hline Sources & Sum of Squares $(S S)$ & $\begin{array}{l}\text { Degree of freedom } \\
(d . f)\end{array}$ & Mean Square $(M S)$ & $\begin{array}{c}F- \\
\text { value }\end{array}$ & $F_{0.05}$ \\
\hline \multicolumn{6}{|c|}{ Percentage removal of MB } \\
\hline Regression (SSR) & 9416.93 & 14 & 672.64 & 2.88 & $>2.74$ \\
\hline Residual & 2564.89 & 11 & 233.17 & & \\
\hline Total $(S S T)$ & 11981.83 & 25 & & & \\
\hline
\end{tabular}

Figure 2 illustrates the Pareto chart and p-values of variables in Equation (4). The p-values are a technique for determining the effect of each coefficient. Each coefficient signifies higher relevance when the corresponding coefficient indicates fewer p-values or a larger magnitude t-value. As shown in Figure 2, the most significant effect on percent removal of $\mathrm{MB}$ is the linear term of effect of initial $\mathrm{pH}\left(\mathrm{X}_{2}\right)$ with the smaller $\mathrm{p}$-value $(0.000001)$ and largest $\mathrm{t}$-values (9.9365) as $95 \%$ significant level. For interaction term of adsorbent dosage and initial $\mathrm{pH}\left(\mathrm{X}_{1} \mathrm{X}_{2}\right)$, quadratic term of initial $\mathrm{pH}\left(\mathrm{X}_{2}^{2}\right)$, the interaction term of adsorbent dosage and initial concentration $\left(\mathrm{X}_{1} \mathrm{X}_{3}\right)$, and linear term of adsorbent dosage effect $\left(\mathrm{X}_{1}\right)$ could also be regarded as significant factors in affecting the percent removal of MB due to large t-values of $3.5076,-3.1151,2.8022$, and 2.6871, respectively.

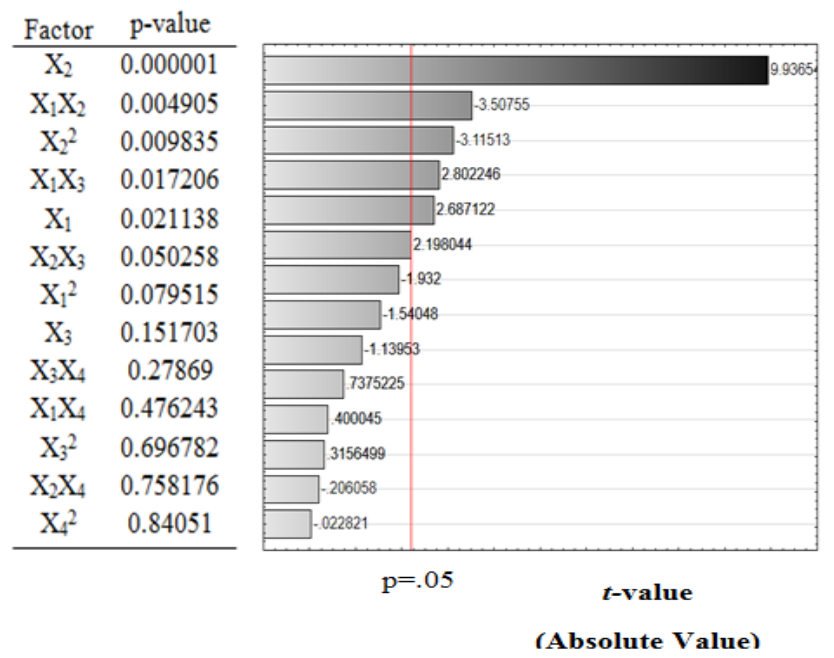

Figure 2. Pareto chart and $p$-value

The response surfaces are commonly used to assess the relationships between parameters and to forecast the outcome under particular circumstances. Six RSM 3-D plots between four parameters for the percent removal of MB model were generated and plotted as a function of two variables, with the others held constant at their mean values. Figure 3A shows a response surface plot of the percent removal of $\mathrm{MB}$ as a function of adsorbent dosage and initial $\mathrm{pH}$. According to the examination of the response surface plot, initial $\mathrm{pH}$ value has a more significant influence on the response surface than adsorbent dosage. This can be explained by the Pareto chart (Figure 2), in which initial pH value has a higher t-value (9.9366) than adsorbent dosage (2.6871). The percent removal of $\mathrm{MB}$ rose as the initial $\mathrm{pH}$ value increased, peaking at pH 7 and then continuously increased as the adsorbent dosage increased until the maximum concentratoin of $1.4 \mathrm{~g} / \mathrm{L}$. The positive charge on the solution interface decreased as the $\mathrm{pH}$ climbed from $\mathrm{pH} 2$ to 7 , and the adsorbent surface appears to be negatively charged, rendering MB to rapidly adsorbed onto the surface of IC [15]. 

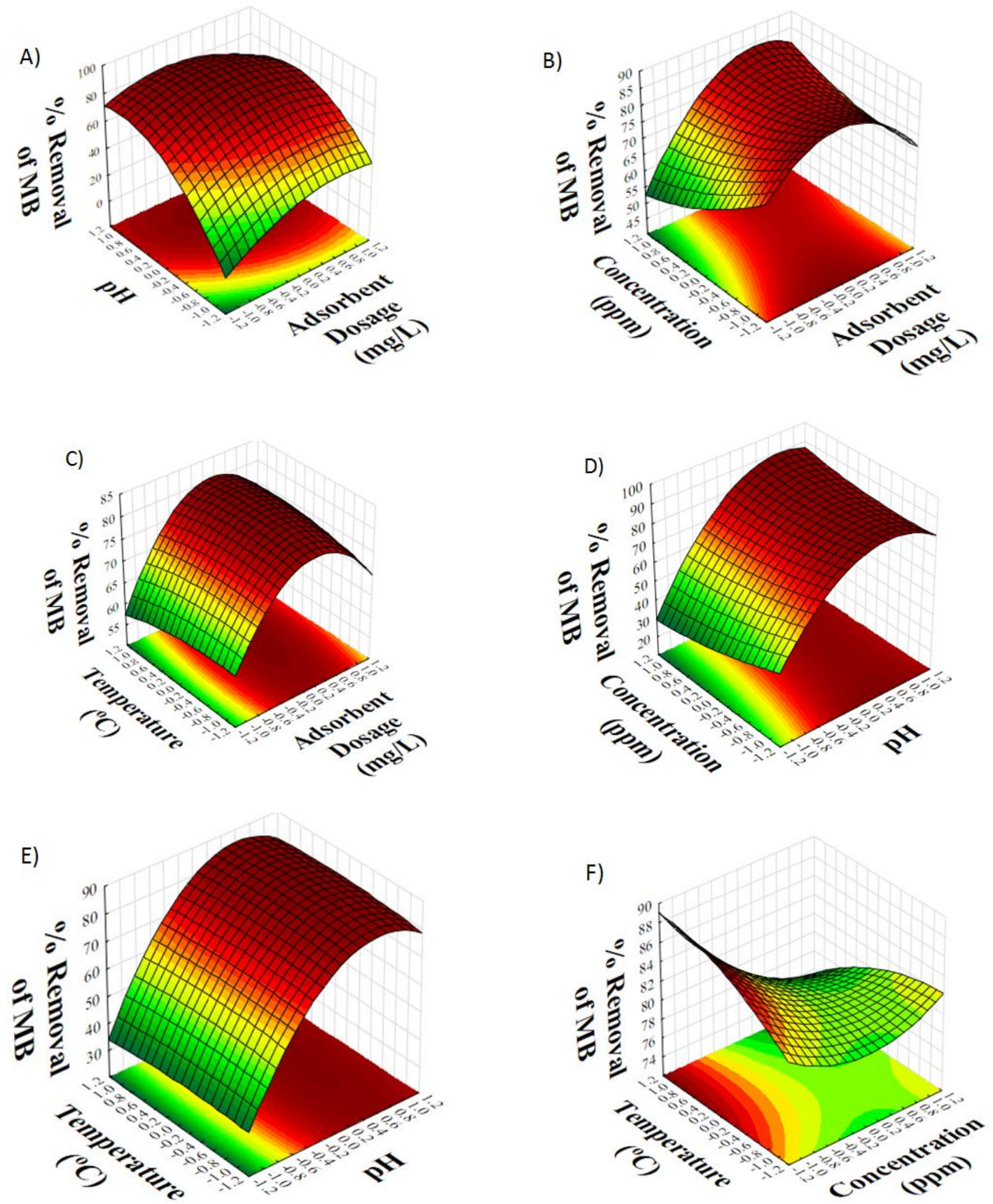

Figure 3. Response surface plot of combined (A) adsorbent dosage and $\mathrm{pH},(\mathrm{B})$ initial concentration and adsorbent dosage, $(\mathrm{C})$ adsorbent dosage and temperature, $(\mathrm{D})$ concentration and $\mathrm{pH},(\mathrm{E})$ temperature and $\mathrm{pH}$ and $(\mathrm{F})$ temperature and concentration.

Figure 3B represents the effect of adsorbent dosage and concentration of $\mathrm{MB}$ on removal of $\mathrm{MB}$. The increment of initial concentration of MB slightly affected the adsorption process, thus decreasing the percent removal of MB. As the initial MB concentration rises, the mass transfer driving force increases, resulting in less MB adsorption [16]. At low concentrations, the removal of MB only increases as the adsorbent dosage increases. However, for a higher removal of $\mathrm{MB}$, a high concentration combined with a large adsorbent dose is required. This indicates that adsorption is strongly dependent on the dye concentration at the start. The initial number of dye molecules to accessible surface area ratio is low at lower concentrations. As a result, fractional adsorption is no longer dependent on the initial concentration. However, when the concentration increases, the number of accessible adsorption sites decreases, and as a result, the percentage of dye removed is proportional to the initial concentration. Figure $3 \mathrm{C}$ shows that the temperature of the $\mathrm{MB}$ solution has a minor impact on the removal of $\mathrm{MB}$, whereas the adsorbent dosage has a considerable impact on the removal of $\mathrm{MB}$. The adsorption of MB was marginally reduced when the surface coverage decreased. The surface area of the adsorbent is reduced as dye penetrates inside micro-pores or a new site is created at a higher temperature.

Figure 3D shows that the initial $\mathrm{pH}$ has a greater impact on the removal of $\mathrm{MB}$ than the initial MB concentration. This can be described by the bigger t-value of the initial $\mathrm{pH}$ value (9.9365) as compared to initial concentration (-1.13953). Figure $3 \mathrm{E}$ further illustrates that $\mathrm{pH}$ has a greater impact on the removal of $\mathrm{MB}$ as compared to temperature. This can be 
elucidated by the bigger t-value of the initial $\mathrm{pH}$ value (9.9365) as compared to temperature (-2.0605). With an increase in the initial $\mathrm{pH}$ value, a progressive increase in the removal of $\mathrm{MB}$ was observed. However, after reaching the maximum, the percent removal of $\mathrm{MB}$ falls slightly when the initial $\mathrm{pH}$ value rises. The effect of temperature on the removal of $\mathrm{MB}$ was insignificant at constant $\mathrm{pH}$. On the other hand, the relationship between temperature and MB concentration was not significant, as shown in Figure 3F. It is clear that these two variables, have little impact on MB adsorption. This finding is suppported by the greater t-value of initial concentration (-1.13953) as compared to temperature (-2.0605) [17]. This observation is in agreement with the finding shown in Figure $3 \mathrm{~F}$, whereby the temperature has little effect on the adsorption of $\mathrm{MB}$ for the response surface plot of combined temperature and concentration.

In summary, all of the parameters appeared to have an impact on the percent removal of $\mathrm{MB}$, but the initial $\mathrm{pH}$ appears to be the most important, in agreement with the greater t-value (9.9365). This is due to the fact that the $\mathrm{pH}$ affects not only the surface charge of the adsorbent in the solution, but also the degree of ionisation and dissociation of the functional groups on the active sites.

The optimum condition was forecasted from the reponse surface analysis, and the forecasted optimum percent removal of $\mathrm{MB}$ is $86.61 \%$, at an adsorbent dosage of $1.458 \mathrm{~g} / \mathrm{L}$, temperature of $42{ }^{\circ} \mathrm{C}$, initial $\mathrm{pH}$ of 6.8 and concentration of $\mathrm{MB}$ of $235 \mathrm{ppm}$. Validation of optimized result was conducted by comparing the observed value with the forecast value. The error $(1.3 \%)$ was considered small within the $5 \%$ level of significance.

\section{Characterization of adsorbent}

The appearance and structure of the IC surface were studied using SEM before and after the 50-minute adsorption process, as illustrated in Figure 4. As shown in Figure 4a, IC has a rough surface with a heterogeneous porous and cavity structure. This suggests that MB dye could be trapped and absorbed into the surface of IC. However, the SEM image of IC after adsorption (Figure 4b) indicated that the caves, pores, and surfaces have been coated with MB.
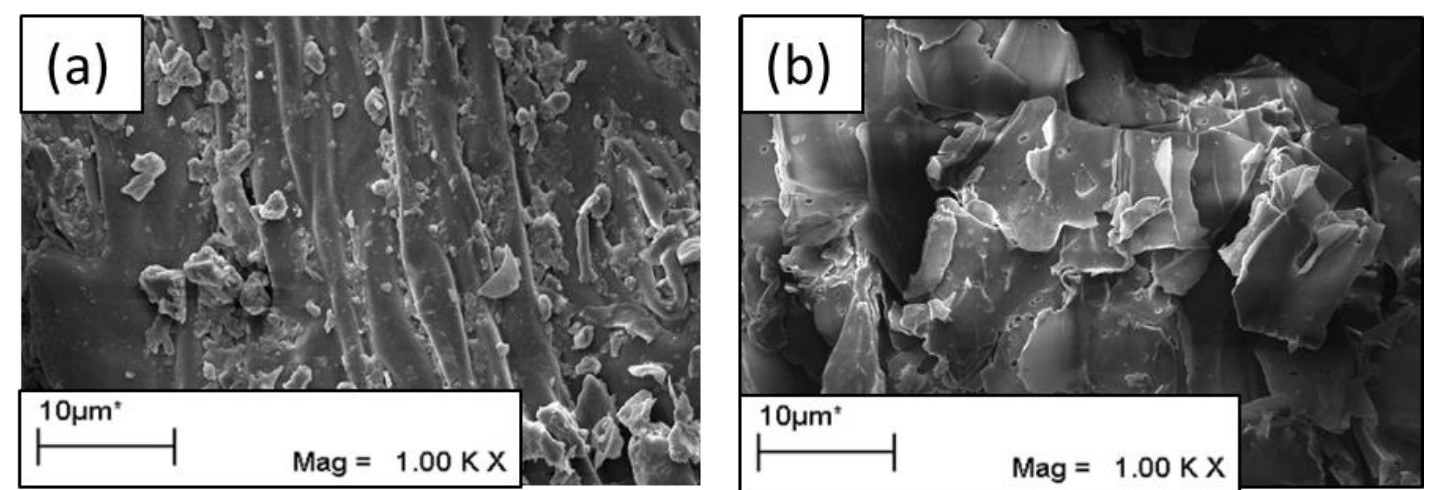

Figure 4. SEM micrograph of (a) IC before adsorption process (b) IC after 50 min of the adsorption process

The FTIR spectra of IC before and after the MB adsorption are shown in Figure 5. The broad peaks detected at 3434 and $3435 \mathrm{~cm}^{-1}$ could be assigned to $\mathrm{O}-\mathrm{H}$ stretching vibration of hydroxyl functional group [18]. Meanwhile, the peaks at $2800-2852 \mathrm{~cm}^{-1}$ and $1602-1740 \mathrm{~cm}^{-1}$ were assigned to $\mathrm{C}-\mathrm{H}$ stretching vibration and $\mathrm{NH}_{2}$ deformation [19]. The intensities of the peaks become weaker after the adsorption process because the surface of the IC was occupied with the MB, and it slows down the adsorption process. Other peaks detected on IC before adsorptions were located at $1164 \mathrm{~cm}^{-1}$ assigned to C-N stretching vibration [20]. Nevertheless, these functional group disappeared after MB adsorption. The FTIR analysis indicated that IC has a lot of absorption peaks, which reflects the adsorbent's complex composition. The alterations in the spectrum after MB adsorption suggested the participation of the IC's functional groups in the MB adsorption process.

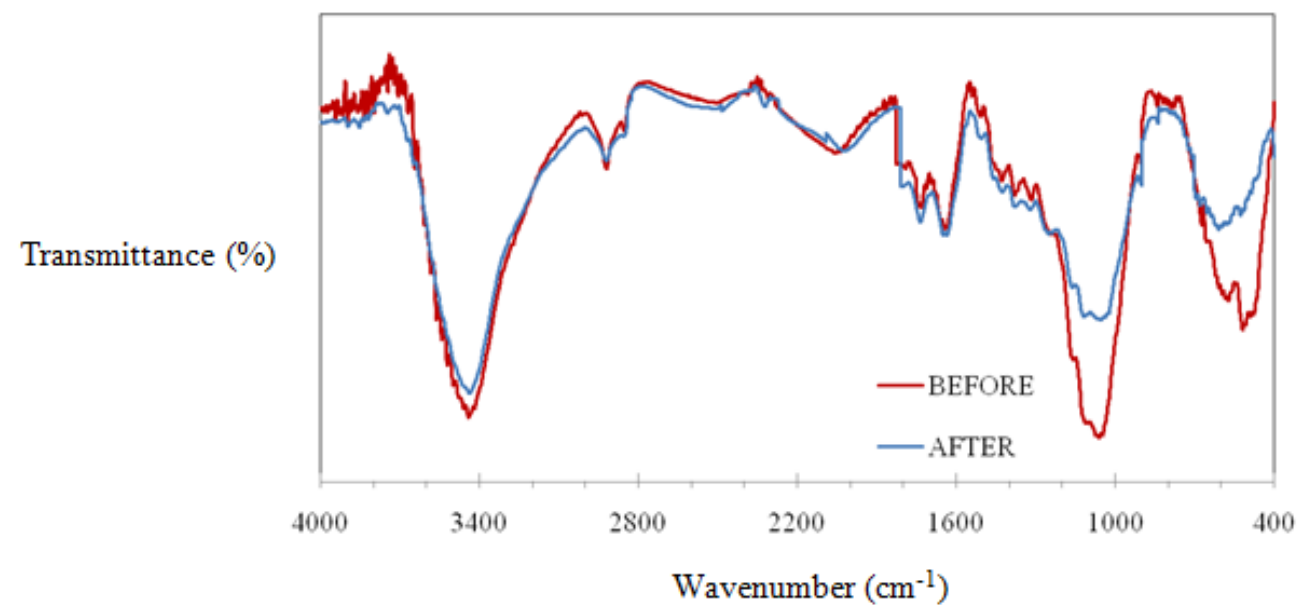

Figure 5. FTIR spectra of IC before and after MB adsorption 


\section{CONCLUSION}

In summary, the IC as a low-cost adsorbent were succesfully sythesized to remove colors from wastewater. This work also studies the reaction optimization of Methylene Blue (MB) removal using IC by RSM. The RSM experiments were designed with 4 independent variables (initial adsorbent dosage, initial $\mathrm{pH}$, initial dye concentration, and initial temperature) and 1 response variable (percent removal of $\mathrm{MB}$ ). According to the pareto figure, the initial $\mathrm{pH}$ has the greatest impact on the percent removal of MB. The RSM data predicted the optimum condition of MB removal up to $86.61 \%$ using IC, obtained by utilizing adsorbent dosage of $1.458 \mathrm{~g} / \mathrm{L}$, at $42^{\circ} \mathrm{C}$, with initial $\mathrm{pH}$ of 6.8 and $\mathrm{MB}$ concentration of $235 \mathrm{ppm}$. The chacterization analysis confirmed the role of the IC's physicochemical properties in the adsoprtion process. The combined effects of independent variables (adsorbent dosage, $\mathrm{pH}$, initial concentration, and temperature) on response (\% MB removal) were investigated using $\mathrm{RSM}$. The linear term of the initial $\mathrm{pH}$ was greatest effect, according to the Pareto chart. The predicted value for the percent removal of MB at the optimum condition is $86.6 \%$, respectively, with a small error of $1.3 \%$. The optimum conditions for the removal of MB were observed at 1.458 $\mathrm{g} / \mathrm{L}$ of IC, $\mathrm{pH} 6.8,235 \mathrm{ppm}$ of $\mathrm{MB}$ concentration, and $42{ }^{\circ} \mathrm{C}$. As a conclusion, these findings are useful for designing adsorbents, as well as other materials for various applications.

\section{ACKNOWLEDGMENT}

We would like to thank the School of Health Sciences, Health Campus, Universiti Sains Malaysia for the technical assistance and supports in this work.

\section{REFERENCES}

[1] R. P. Singh, P. K. Singh, R. Gupta, and R. L. Singh, "Treatment and Recycling of Wastewater from Textile Industry," pp. 225-266, 2019, DOI: 10.1007/978-981-13-1468-1_8

[2] A. E. Al Prol, "Study of Environmental Concerns of Dyes and Recent Textile Effluents Treatment Technology: A Review," Asian J. Fish. Aquat. Res., vol. 3, no. 2, pp. 1-18, 2019, doi: 10.9734/ajfar/2019/v3i230032.

[3] E. M. Ijanu, M. A. Kamaruddin, and F. A. Norashiddin, "Coffee processing wastewater treatment: a critical review on current treatment technologies with a proposed alternative," Appl. Water Sci., vol. 10, no. 1, pp. 1-11, 2020, doi: 10.1007/s13201019-1091-9.

[4] V. Katheresan, J. Kansedo, and S. Y. Lau, "Efficiency of various recent wastewater dye removal methods: A review," J. Environ. Chem. Eng., vol. 6, no. 4, pp. 4676-4697, 2018, doi: 10.1016/j.jece.2018.06.060.

[5] N. A. Bakar et al., "An insight review of lignocellulosic materials as activated carbon precursor for textile wastewater treatment," Environ. Technol. Innov., vol. 22, p. 101445, 2021, doi: 10.1016/j.eti.2021.101445.

[6] W. J. Yang et al., "Carbon quantum dots (CQDs) nanofiltration membranes towards efficient biogas slurry valorization," Chem. Eng. J., vol. 385, no. October 2019, p. 123993, 2020, doi: 10.1016/j.cej.2019.123993.

[7] S. Nag, A. Mondal, N. Bar, and S. K. Das, "Biosorption of chromium (VI) from aqueous solutions and ANN modelling," Environ. Sci. Pollut. Res., vol. 24, no. 23, pp. 18817-18835, 2017, doi: 10.1007/s11356-017-9325-6.

[8] Z. Jiang and D. Hu, "Molecular mechanism of anionic dyes adsorption on cationized rice husk cellulose from agricultural wastes," J. Mol. Liq., vol. 276, pp. 105-114, 2019, doi: 10.1016/j.molliq.2018.11.153.

[9] H. A. Chanzu, J. M. Onyari, and P. M. Shiundu, "Brewers' spent grain in adsorption of aqueous Congo Red and malachite Green dyes: Batch and continuous flow systems," J. Hazard. Mater., vol. 380, no. March, p. 120897, 2019, doi: 10.1016/j.jhazmat.2019.120897.

[10] N. Srinivasababu, Understanding the durability of long sacred grass/Imperata cylindrica natural/hybrid FRP composites. Elsevier Ltd, 2018.

[11] L. Bulgariu et al., "The utilization of leaf-based adsorbents for dyes removal: A review," J. Mol. Liq., vol. 276, pp. 728-747, 2019, doi: 10.1016/j.molliq.2018.12.001.

[12] H. J. Hadi, K. M. M. Al-Zobai, and M. J. A. Alatabe, "Oil removal from produced water using Imperata cylindrica as lowcost adsorbent," Curr. Appl. Sci. Technol., vol. 20, no. 3, pp. 494-511, 2020, doi: 10.14456/cast.2020.33.

[13] M. Jaafar, A. Alatabe, and N. O. Kariem, "Using Imperata cylinderica as Natural Low-Cost Biosorbent for Rapid and Efficient Removal of Zinc ( II ) Ions from Aqueous Solutions," vol. 48, pp. 1226-1232, 2021.

[14] C. X. H. Su, T. T. Teng, A. F. M. Alkarkhi, and L. W. Low, "Imperata cylindrica (cogongrass) as an adsorbent for methylene blue dye removal: Process optimization," Water. Air. Soil Pollut., vol. 225, no. 5, 2014, doi: 10.1007/s11270-014-1941-x.

[15] M. B. Ahmad, U. Soomro, M. Muqeet, and Z. Ahmed, "Adsorption of Indigo Carmine dye onto the surface-modified adsorbent prepared from municipal waste and simulation using deep neural network," J. Hazard. Mater., vol. 408, no. September 2020, p. 124433, 2021, doi: 10.1016/j.jhazmat.2020.124433.

[16] A. B. Albadarin, M. N. Collins, M. Naushad, S. Shirazian, G. Walker, and C. Mangwandi, "Activated lignin-chitosan extruded blends for efficient adsorption of methylene blue," Chem. Eng. J., vol. 307, pp. 264-272, 2017, doi: 10.1016/j.cej.2016.08.089.

[17] R. Hasan and H. D. Setiabudi, "Removal of Pb(II) from aqueous solution using KCC-1: Optimization by response surface methodology (RSM)," J. King Saud Univ. - Sci., vol. 31, no. 4, pp. 1182-1188, 2019, doi: 10.1016/j.jksus.2018.10.005.

[18] R. Amiri, E. Khamehchi, and M. Ghaffarzadeh, "Experimental investigation of a novel multifunctional chemical solution on preventing asphaltene precipitation using two crude oil samples with different molecular properties," J. Mol. Liq., vol. 309, p. 113121, 2020, doi: 10.1016/j.molliq.2020.113121.

[19] S. K. Gaonkar and I. J. Furtado, "Valorization of low-cost agro-wastes residues for the maximum production of protease and lipase haloextremozymes by Haloferax lucentensis GUBF-2 MG076078," Process Biochem., vol. 101, no. June 2020, pp. 72 88, 2021, doi: 10.1016/j.procbio.2020.10.019.

[20] F. MaryAnjalin, N. Kanagathara, R. Gowri Shankar Rao, M. K. Marchewka, and S. Pugazhendhi, "Structural and spectroscopic aspects on anilinium hydrogen oxalate hemiihydrate," Mater. Today Proc., vol. 33, pp. 1049-1057, 2020, doi: 10.1016/j.matpr.2020.07.056. 